\title{
Systemic adjuvant therapies in renal cell carcinoma
}

\author{
Sebastiano Buti, ${ }^{1}$ Melissa Bersanelli, ${ }^{1}$ Maddalena Donini, ${ }^{2}$ Andrea Ardizzoni' \\ 'Operative Unit of Medical Oncology, University Hospital of Parma; ${ }^{2}$ Oncology Division, Istituti \\ Ospitalieri di Cremona, Italy
}

\begin{abstract}
Renal cell carcinoma (RCC) is one of the ten most frequent solid tumors worldwide. Recent innovations in the treatment of metastatic disease have led to new therapeutic approaches being investigated in the adjuvant setting. Observation is the only current standard of care after radical nephrectomy, although there is evidence of efficacy of adjuvant use of vaccine among all the strategies used. This article aims to collect published experiences with systemic adjuvant approaches in RCC and to describe the results of past and ongoing phase III clinical trials in this field. We explored all the systemic treatments, including chemotherapy, immunotherapy and targeted drugs while alternative approaches have also been described. Appropriate selection of patients who would benefit from adjuvant therapies remains a crucial dilemma. Although the international guidelines do not actually recommend any adjuvant treatment after radical surgery for RCC, no conclusions have yet been drawn pending the results of the promising ongoing clinical trials with the target therapies. The significant changes that these new drugs have made on advanced disease outcome could represent the key to innovation in terms of preventing recurrence, delaying relapse and prolonging survival after radical surgery for RCC.
\end{abstract}

Correspondence: Sebastiano Buti, Operative Unit of Medical Oncology, University Hospital of Parma, via Gramsci 14, 43100 Parma, Italy.

Tel. +39.0521.702661. E-mail: sebabuti@libero.it

Key words: renal cell carcinoma, adjuvant therapy, immunotherapy.

Contributions: SB, study conception and design, data acquisition and interpretation, paper drafting and revising; MB, study conception and design, data research and revision, analysis and interpretation of the revised studies, paper drafting; MD, study conception and design, data research and analysis, paper drafting; $\mathrm{AA}$, paper, data selection and interpretation, paper drafting and revising; all authors have given their approval of the final version to be published.

Conflict of interests: the authors have no conflict of interests.

Received for publication: 29 March 2012.

Revision received: 3 July 2012.

Accepted for publication: 5 July 2012.

This work is licensed under a Creative Commons Attribution NonCommercial 3.0 License (CC BY-NC 3.0).

(C) Copyright S. Buti et al., 2012

Licensee PAGEPress, Italy

Oncology Reviews 2012; 6:e18

doi:10.4081/oncol.2012.e18

\section{Introduction}

Renal cell carcinoma (RCC) is the ninth most common cancer in women and the seventh in men. It is responsible for $2-3 \%$ of all malignant cancers in adults. The RCC incidence worldwide is 209,000 new cases and 102,000 deaths each year. ${ }^{1,2}$ Incidence rates have almost doubled over the past 30 years from 7.1 per 100,000 in 1975 to an ageadjusted incidence rate of 14.6 per 100,000 men and women per year in 2004-2008. The age-adjusted death rate was 4.0 per 100,000 men and women per year in the United States in 2004-2008..$^{2-4}$ The disease is predominant in men and usually occurs during the sixth or seventh decade of life. The best known risk factors are tobacco smoking, obesity and hypertension; also occupational risks have been evidenced, such as exposure to steel, iron, asbestos, cadmium and petroleum. Finally, genetic conditions such as Von Hippel Lindau syndrome, hereditary papillary renal carcinoma and Birt-Hogg-Dubé syndrome are forms of inherited RCC. ${ }^{4-6}$

The American Joint Committee on Cancer (AJCC) describes five subtypes of RCC: conventional (clear cell), papillary, chromophobe, collecting duct and unclassified. ${ }^{7}$ Clear cell carcinoma represents about $80 \%$ of RCCs and is the most used in clinical trials as a pattern for therapy and prognosis.

The main therapeutic approach in early RCC is surgery, with radical or partial nephrectomy. Recent years have seen both these techniques evolve and they can now be performed safely by laparoscopy. ${ }^{8-10}$ For smaller tumors, the nephron sparing technique should always be considered. Partial nephrectomy has been proven to be as effective as radical nephrectomy in carefully selected cases. ${ }^{11,12}$

The strongest indicator of prognosis in RCC is stage at diagnosis. Using 2010 TNM staging criteria, the reported 5-year survival rates range from $81 \%$ in stage I to $8 \%$ in stage IV..$^{13}$

Approximately $30 \%$ of patients with RCC have metastatic disease at presentation and there is disease recurrence in approximately $40 \%$ of patients initially treated for a localized disease. ${ }^{14}$ The median time to relapse after nephrectomy is $15-18$ months, and $85 \%$ of relapses occur within three years. ${ }^{15}$

Several factors are associated with a worse prognosis after radical nephrectomy and correlate strongly with survival: regional lymph node involvement, ${ }^{16}$ histological features (Fuhrman nuclear grading, presence of necrosis, microvascular invasion, sarcomatoid, papillary or chromophobe features), ${ }^{17-23}$ stage and nuclear grade, ${ }^{22}$ tumor size. ${ }^{24}$ Variables related to the patient also influence prognosis: a low performance status, the presence of symptoms at the moment of diagnosis, cachexia and alterations in some laboratory parameters are related to a worse prognosis. ${ }^{16}$ Finally, some molecular markers have demonstrated a prognostic value in RCC: a low expression of the transmembrane carbonic anhydrase IX (CAIX), ${ }^{25-29}$ elevated serum vascular endothelial growth factor (VEGF) level ${ }^{30}$ and other biomarkers whose weight and role are still to be defined. ${ }^{25,31}$

The recent discovery of new prognostic factors led to the develop- 
ment of prognostic nomograms and algorithms that are very useful for stratifying patient risk of relapse. Among the best known of these models is the Memorial Sloan-Kettering Cancer Center (MSKCC) nomogram, including pathological stage, Fuhrman nuclear grading, tumor size, necrosis, vascular invasion and clinical presentation, ${ }^{32}$ the University of California Los Angeles Integrated Staging System (UISS), based on Eastern Cooperative Oncology Group (ECOG) performance status, Fuhrman nuclear grading and pathological stage according to the 2002 TNM staging system, ${ }^{33}$ the Mayo Clinic Stage Size Grade and Necrosis (SSIGN) score, that takes into consideration TNM stage, tumor size, nuclear grade and histological tumor necrosis, ${ }^{34}$ the Karakiewicz nomogram, based on TNM stage, Fuhrman grade, histological subtype, local symptoms, age, and sex ${ }^{35}$ the Leibovich score, including tumor stage, regional lymph node status, tumor size, nuclear grade, histological tumor necrosis and with the recent addition of scoring for vascular invasion, with a higher predictive accuracy ${ }^{36-39}$ Several comparative studies have been performed to assess the best predictive value among all these different nomograms. Two retrospective studies comparing SSIGN and Leibovich scores with UISS score suggested that the SSIGN and Leibovich scores offer a better stratification for clear cell RCC than the UISS model. ${ }^{40,41}$ More recently, the Karakiewicz nomogram emerged as a better clinical predictor for survival outcomes in patients with localized disease when compared to the Leibovich model. ${ }^{41,42}$ The risk stratification offered by these nomograms for individual patients is necessary in order to develop tailored treatments that could reduce the risk of relapse and enhance the chance of successful disease management; in the context of adjuvant treatment, these algorithms are useful to better select which patients should be enrolled in ongoing clinical trials with new molecules.

Regarding the current standard of care after radical surgery, the most recent National Comprehensive Cancer Network (NCCN) Guidelines for kidney cancer declared that adjuvant treatment currently has no established role. This was based on the absence of any sistemic therapy capable of reducing the likehood of relapse. ${ }^{42}$ For the moment, observation remains the standard of care after nephrectomy, with the possibility of enrollment in randomized clinical trials reserved only for eligible patients. A meta-analysis of ten studies on various systemic adjuvant therapy in RCC was recently performed by Scherr et al. ${ }^{43}$ The authors examined randomized controlled trials and compared adjuvant therapy versus observation after surgery. They analyzed the outcome as overall survival (OS), disease free survival (DFS) and severe toxicities. Different strategies of treatment were evaluated separately: subgroup analysis among immunotherapy, hormone therapy, biochemotherapy and vaccines showed no relevant results. The adjuvant therapy provided no benefits in terms of $\mathrm{OS}(\mathrm{HR}=1.07,95 \% \mathrm{CI}$ 0.89-1.28; $\mathrm{P}=0.48$; no heterogeneity) or DFS (HR=1.03, 95\% CI 0.87 $1.21, \mathrm{P}=0.77$; heterogeneity measured as $\mathrm{I}^{2}=40 \%$ ) when compared with no treatment. Evaluation of toxicity showed a higher incidence of adverse events in the adjuvant therapy groups. ${ }^{43}$ Development of an adjuvant therapy requires an evidence-based approach and an in-depth knowledge of the molecular basis of the disease. An effective adjuvant drug for RCC should be relatively non-toxic, have estabilished efficacy in the metastatic setting (with the exception of immunotherapy, which was shown to be more effective for residual and indolent disease) and have demonstrated efficacy against the standard of care in randomized trials. A gain in OS should be considered as criteria for efficacy of adjuvant treatment. Furthermore, the appropriate identification of patients at the highest risk of relapse, or who are more sensitive to particular drugs as potential beneficiaries of this treatment approach, is a crucial question in the adjuvant setting. Indeed, our ability to predict relapse has much room for improvement. Finally, we should consider that patients with low risk of recurrence are not ideal candidates for adjuvant treatment.

\section{Methods of research}

The purpose of the present study is to review the most up-to-date literature in systemic adjuvant treatment for RCC after radical surgery; phase III randomized trials have been included. Publications on adjuvant therapy for RCC were obtained from the Pubmed database using the subsequent MeSH (Medical Subject Heading) terms: CHEMOTHERAPY and IMMUNOTHERAPY and CANCER VACCINES and ADJUVANT, each combined with CARCINOMA, RENAL CELL. We also used combinations of the following words: KIDNEY CANCER and POSTOPERATIVE TREATMENT and CHEMOTHERAPY and IMMUNOTHERAPY and VACCINES and ADJUVANT THERAPY and RANDOMIZED CONTROLLED TRIALS. The ongoing randomized phase III clinical trials were obtained on the official website (www.clincaltrials.gov). The search was completed by exploring the abstract databases from the most important international scientific meetings.

\section{Adjuvant immunotherapy}

Immunotherapy for RCC has been available for the past 30 years: the ability of renal cancer to evoke an immune response led to the use of immunotherapy for patients with metastatic RCC. Different strategies have been explored in an attempt to reproduce and to improve the natural immune response. The most consistent results have been reported both with the vaccines and with cytokines [interleukin-2 (IL-2) and interferon-alpha (IFN- $\alpha)]$, used alone or in combination. The cytokines increased both the activity of cytotoxic lymphocytes and of natural killer (NK) cells, modulating, as vaccines, the host immune system response to tumor cells. ${ }^{44}$

Several randomized trials have been performed to assess the efficacy of immunotherapy in the adjuvant setting (Table 1), ${ }^{45-50}$ but most have failed to show any survival advantage.

IFN- $\alpha$ modulates cell growth and function, directly inhibiting cell proliferation and regulating the antigenic differentiation and expression of the cell. It is one of the active drugs in metastatic disease and has been shown to improve survival in metastatic RCC patients. ${ }^{44,51-53}$

Table 1. Adjuvant immunotherapy trials in renal cell cancer.

\begin{tabular}{|c|c|c|c|c|c|}
\hline Author & $\begin{array}{l}\text { No. } \\
\text { patients }\end{array}$ & Stage & Treatment & $\begin{array}{l}\text { Primary } \\
\text { end point }\end{array}$ & Results \\
\hline $\begin{array}{l}\text { Pizzocaro } \\
\text { et al., } 2001^{45}\end{array}$ & 247 & $\begin{array}{l}\text { Robson } \\
\text { II-III* }\end{array}$ & IFN- $\alpha-2 b$ & OS & $\begin{array}{c}\text { No difference } \\
\text { in RFS or OS } \\
\text { Harmful in N0 } \\
\text { Possibly protective } \\
\text { in pN2-3 in terms } \\
\text { of RFS }\end{array}$ \\
\hline $\begin{array}{l}\text { Clark } \\
\text { et al., } 2003^{46}\end{array}$ & $69 \mathrm{p}$ & $\begin{array}{l}\text { T3b-4, pN1-3, } \\
\text { esected Ml }\end{array}$ & IL-2 & DFS & $\begin{array}{c}\text { No difference in DFS } \\
\text { or OS }\end{array}$ \\
\hline $\begin{array}{l}\text { Messing } \\
\text { et al., } 2003^{47}\end{array}$ & 283 & $\begin{array}{c}\text { pT3-T4a, } \\
\text { pN1-3 }\end{array}$ & IFN- $\alpha$ & OS & $\begin{array}{c}\text { No difference } \\
\text { in OS }\end{array}$ \\
\hline $\begin{array}{l}\text { Passalacqua } \\
\text { et al., } 200748\end{array}$ & 310 & $\begin{array}{l}\text { pT1 over } \\
2.5 \mathrm{~cm} \text {, } \\
\text { T2-T3, pN0-3 }\end{array}$ & IL-2+IFN- $\alpha$ & OS & $\begin{array}{l}\text { No difference in RFS } \\
\text { No difference in OS }\end{array}$ \\
\hline $\begin{array}{l}\text { Hinotsu } \\
\text { et al., 2011 }\end{array}$ & 107 & $\begin{array}{l}\text { Stage } \\
\text { II and III }\end{array}$ & IFN- $\alpha$ & PFS & No difference in PFS \\
\hline
\end{tabular}

IL-2, interleukin-2; IFN- $\alpha$, interpheron- $\alpha$; OS, overall survival; RFS, relapse free survival; DFS, disease free survival; PFS, progression free survival (intended as recurrence free survival). *According to the Robson Staging System. ${ }^{50}$ 
The randomized studies of adjuvant therapy with IFN- $\alpha$ provided substantial evidence for a detrimental trend for treated patients. In 2001, Pizzocaro et al. ${ }^{45}$ published the results of a multicentric randomized study of adjuvant interferon in patients with stage II or III RCC, randomized after surgery to observation or to IFN- $\alpha 2 b$ (6 million IU intramuscularly 3 times per week for six months starting within one month from surgery). In a comparison of relapse free survival (RFS), 51 of 123 patients in the treatment arm, compared to 38 of 124 patients in the control arm, had recurrent disease at a median follow up of 62 months. The study showed no advantage for adjuvant IFN- $\alpha 2 b$ therapy over observation in terms of overall and event free survival. A harmful effect of IFN- $\alpha 2 \mathrm{~b}$ in the treated pN0 patients and a protective effect in the treated pN2/pN3 patients were statistically significant, but these findings require further investigation because of the small size of these subgroups.

In the phase III clinical trial conducted by the ECOG in 2003, a total of 283 patients with pT3-4a and/or node-positive resected disease were randomly assigned to receive up to 12 cycles of IFN- $\alpha$-NL (Wellferon) administered daily for five days every three weeks ( 3 million $\mathrm{U} / \mathrm{m}^{2}$ Day 1, 5 million $\mathrm{U} / \mathrm{m}^{2}$ Day 2,20 million $\mathrm{U} / \mathrm{m}^{2}$ Days 3,4 and 5 by intramuscular injection) or to observation until recurrence or progression was confirmed. The primary end point of the study was to compare survival. At median follow up of 10.4 years, median $0 \mathrm{~S}$ was 7.4 years in the observation arm and 5.1 year in the treatment arm (log rank $\mathrm{P}=0.09)$. Median RFS, defined as time from random assignment of treatment to recurrence or death, although not significant, was longer in observed patients: three years in the observation arm versus 2.2 years in the interferon arm. Although no lethal toxicities were observed, severe toxicities occurred in $11.4 \%$ of those randomly assigned to interferon treatment. ${ }^{47}$ It was concluded that adjuvant treatment with interferon did not contribute to improving the outcome in the study group.

In recent years, Hinotsu et al. have tried to prolong exposure to the prophylactic postoperative immunotherapy, performing a trial on the efficacy of 1-year postoperative administration of natural IFN- $\alpha$ in RCC patients who underwent radical nephrectomy. The results, published in 2011, evidenced a not statistically significant difference for the primary end point, represented by the progression free survival (the authors intend PFS as recurrence free survival), between the groups that received natural IFN- $\alpha$ or follow-up observation $(\mathrm{P}=0.456$, log rank test). However, peak hazards of progression in the IFN- $\alpha$ group were delayed for approximately 6-10 months compared with the observation group, underlining the importance of a longer follow up in the adjuvant studies. ${ }^{49}$

IL-2 is a growth factor and activator of both T cells and NK cells, produced and released by activated $\mathrm{T}$ cells. The Food and Drug Administration (FDA) approved its use for therapy in metastatic RCC in $1992 .{ }^{54}$ Currently, high-dose IL-2 remains the only agent with proven efficacy in producing durable complete and partial responses in the metastatic setting. ${ }^{50}$

IL-2 high-dose bolus was tested as adjuvant therapy in a single randomized trial: 69 patients with locally advanced stage after nephrectomy or with a single surgically resected metastases were randomized to observation or to a single cycle of IL-2: 600,000 IU/kg every eight hours, Days 1-5 and 15-19 for a maximum of 28 doses. The study was designed and powered to show an improvement in predicted 2-year DFS from $40 \%$ for the observation group to $70 \%$ for the treatment group; early closure occurred when an interim analysis determined that the $30 \%$ improvement in 2-year DFS could not be achieved despite full accrual. The study was interrupted early because 15 of 21 patients (71\%) with locally advanced disease in the treatment arm and 16 of 23 (69\%) in the observation arm relapsed at two years, with no significant difference between the two groups. Even in patients with resected metastatic disease, no differences between the two arms were observed. Finally, the investigators concluded that one course of high-dose bolus IL-2, though feasible, did not produce the ambitious clinically meaningful benefit anticipated when administered postoperatively to patients with resected high-risk RCC. ${ }^{46}$

The combination of IL-2 and IFN- $\alpha$ with adjuvant purpose for RCC has also been explored. A multicenter randomized Gruppo Oncologico Italiano di Ricerca Clinica (GOIRC) study, comparing the combination of subcutaneous low-dose IL-2 plus IFN- $\alpha$ versus observation, was presented at the 2007 American Society of Clinical Oncology (ASCO) annual meeting. ${ }^{48}$ The peculiarities of this study are the long duration of immunotherapy treatment, with courses repeated for four weeks every 4-6 months up to five years after surgery, and the inclusion of patients with low risk of relapse, i.e. pT1 or N0 tumors. The trial enrolled 310 patients; intention-to-treat analysis at a median follow up of 52 months showed no significant differences between patients and controls. In the first five years of observation, RFS curves were similar in the two arms, but thereafter diverged. The actuarial RFS at five and ten years was, respectively, $73 \%$ and $73 \%$ in treated patients and $73 \%$ and $60 \%$ in controls (HR $0.84,95 \% \mathrm{CI} 0.54-1.33 \mathrm{P}=0.47$ ). Efficacy of immunotherapy was more evident in patients with good PS (HR 0.78, $95 \% \mathrm{CI} 0.47-1.30, \mathrm{P}=0.35$ ), age under 60 years (HR $0.61,95 \% \mathrm{CI} 0.31$ $1.19, \mathrm{P}=0.15$ ), and low tumor grade (HR $0.70,95 \%$ CI $0.38-1.27$, $\mathrm{P}=0.24)$. No differences in $\mathrm{OS}$ between the two arms were observed. Toxicity was mild in the majority of cases. ${ }^{48}$

\section{Innovation in adjuvant immunotherapy: the vaccines}

Vaccines with antigens derived from tumor cells have been used in an attempt to stimulate the specific immune response against the tumor both in the adjuvant and the metastatic setting for RCC (Table 2). ${ }^{55-57}$ Several vaccines have been tested as adjuvant therapy, including tumor cell lysates and irradiated and cryopreserved preparations of tumor cells. 58

In 1996, in one of the first studies performed, Galligioni et al. randomized 120 patients undergoing nephrectomy for RCC to receive intradermal injections of irradiated autologous tumor cells alone or mixed with Bacillus of Calmette and Guerin versus observation. The treated patients were evaluated for the development of delayed type cutaneous hypersensitivity (DTCH) response to autologous tumor and autologous normal renal cells. After a median follow up of 61 months, there were no differences in OS and in rate of relapse between patients who received adjuvant therapy and controls. ${ }^{55}$ The data obtained clearly indicate that active specific immunotherapy can increase the reactivity to autologous tumor, as measured by the DTCH test, but it appears unable to affect either DFS or OS. More recently, Jocham et al. conducted a multicenter phase III randomized controlled trial using six month-

Table 2. Adjuvant vaccines trials in renal cell cancer.

\begin{tabular}{|c|c|c|c|c|c|}
\hline Author & $\begin{array}{c}\text { No. } \\
\text { patients }\end{array}$ & Stage & Treatment & $\begin{array}{l}\text { Primary } \\
\text { end point }\end{array}$ & Results \\
\hline $\begin{array}{l}\text { Galligioni } \\
\text { et al., } 1996^{55}\end{array}$ & 120 & $\begin{array}{r}\text { pT1-3b, } \\
\text { pN1-3 }\end{array}$ & $\begin{array}{l}\text { Intradermal } \\
\text { vaccination with } \\
\text { BCG mixed } \\
\text { with irradiated cells }\end{array}$ & $\begin{array}{l}\text { DTCH } \\
\text { response } \\
\text { S }\end{array}$ & $\begin{array}{l}\text { Significant DTCH } \\
\text { response to } \\
\text { autologous tumor } \\
\text { No difference in DFS } \\
\text { No difference in OS }\end{array}$ \\
\hline $\begin{array}{l}\text { Jocham } \\
\text { et al., } 2004^{56}\end{array}$ & 558 & $\begin{array}{c}\text { pT2-3b, } \\
\text { pN0-3 }\end{array}$ & $\begin{array}{l}\text { Autologous vaccine } \\
\left.\text { (Reniale }{ }^{\circledR}\right)\end{array}$ & PFS & $\begin{array}{c}\text { Improvement } \\
\text { in the 5-year PFS } \\
\text { No difference in OS }\end{array}$ \\
\hline $\begin{array}{l}\text { Wood } \\
\text { et al., 200557 }\end{array}$ & 728 & $\begin{array}{c}\text { T1b-4, } \\
\text { N1-3 }\end{array}$ & Vitespen ${ }^{\circledR *}$ & RFS & No difference in RFS \\
\hline
\end{tabular}

BCG, Bacillus Calmette-Guérin; OS, overall survival; RFS, relapse free survival; DFS, disease free survival; PFS, progression free survival (including both disease relapse or death); DTCH, delayed type cutaneous hypersensitivity. *An autologous, tumor-derived heat-shock protein glycoprotein 96-peptide complex. 
ly injections of individually prepared autologous renal tumor cell vaccine as adjuvant treatment for patients undergoing radical nephrectomy. ${ }^{56}$ The primary end point of the trial was the reduction of the risk of tumor progression, defined as relapse or death (PFS for the authors). This autologous vaccine was well tolerated and showed a statistically significant benefit when compared with observation. To our knowledge, this is the only adjuvant trial in RCC to date that shows a potential PFS advantage. A total of 379 patients with stage pT2-3b RCC, with or without lymph node involvement and without distant metastasis, were included in the analysis. At 5-year and 70-month follow ups, the hazard ratios for tumor progression were $1.58(95 \% \mathrm{CI} 1.05-2.37)$ and 1.59 (1.07-2.36), respectively, in favor of the vaccine group $(\mathrm{P}=0.02$, log rank test); 5 -year and 70 -month PFS rates were $77.4 \%$ and $72 \%$ in the vaccine group and $67.8 \%$ and $59.3 \%$, respectively, in the control group. The vaccine was well tolerated with only 12 adverse events associated with the treatment. However, $32 \%$ of enrolled patients (174 of 553) were lost after randomization, with a disproportionate number of losses from the treatment group (99 vs 75 from placebo). A criticism of this study, therefore, is that these findings would lose their significance in a true intention-to-treat analysis. ${ }^{59}$ Additionally, OS was not reported in this initial analysis. A secondary one was subsequently performed on 477 patients to include a greater number of patients; this more inclusive intention-to-treat analysis demonstrated a PFS advantage in favor of the treatment group $(\mathrm{P}=0.048)$, although there was no significant difference in $\mathrm{OS}(\mathrm{P}=0.11) .{ }^{60}$ Nevertheless, the use of autologous tumor derived products, especially if personalized and administered to each patient according to the different antigens over-expressed by the individual tumor, appears to be a promising strategy of personalized adjuvant therapy for patients with high-risk RCC. However, the complexity of this procedure makes it difficult to reproduce and use in clinical practice. Wood et al. used an alternative approach to generate a vaccine by the conjunction of peptides from individual tumors with heat-shock proteins. The tumour-derived heat-shock protein glycoprotein 96-peptide complex, called vitespen, was the adjuvant agent of a randomized phase III trial including 818 patients with high risk of recurrence after resection of locally advanced RCC. After a median follow up of 1.9 years, in the intention-to-treat population there was no significant difference in the recurrence rate ( $38 \%$ vs $40 \%$; HR $0.92,95 \%$ CI $0.73-1.17)$. In predefined exploratory analyses by AJCC stage, recurrence events in patients with stage I or II disease were reported in 19 (15\%) patients in the vitespen group and 31 (27\%) in the observation group (HR 0.57, 95\% CI 0.32-1.02; $\mathrm{P}=0.056) .{ }^{57}$ This possible improvement in RFS in patients with early stage disease who received vitespen will require further validation.

Despite the fact that the impact of vaccines on outcome still remains to be proven, all these studies show that this treatment strategy results in a good toxicity profile; this is a very attractive characteristic in the adjuvant setting.

\section{Chemotherapy and chemoimmunotherapy in the adju- vant setting}

The poor sensitivity to chemotherapy of RCC is due to several factors. These include, among others, a high expressions of P-glycoprotein, $\gamma$-glutamyl cysteine synthetase and cis-diamminedichloroplatinum resistance-related gene 9 (CRR9); a low expression of vacuolar ATPase; no expression of multidrug resistance-associated protein 1 (MRP1). ${ }^{61}$ As a result, chemotherapy regimens have a limited role in the treatment of RCC. Both monotherapy (in particular capecitabine) and doublets (gemcitabine plus capecitabine or 5-fluorouracil) have been evaluated in the metastatic setting by several phase II trials. These demonstrated the moderate chemosensibility of RCC, leading to the conclusion that it was not even worth conducting a phase III trial. ${ }^{62-64}$ Nevertheless, some chemotherapy regimens has been tested in the adjuvant setting (Table 3$){ }^{65-67}$

In 1992, Masuda et al. published the results of an adjuvant study with the postoperative administration of vinblastine, doxorubicin and tegafur-uracil in 31 patients with RCC. Even though the 5-year survival rate of $96 \%$ in the treated population was significantly better than that obtained for the historical controls $(60 \%, \mathrm{P}<0.01)$, the methodology of this study, such as low overall risk for chosen patients, small sample size and use of historical cohorts, was fiercely criticised. ${ }^{65}$

Currently, there are no exclusive chemotherapy regimens undergoing evaluation in an adjuvant setting for patients with RCC at high risk of relapse. On the other hand, on the basis of interesting results in metastatic disease, some recent studies have been conducted in the adjuvant setting with combination of cytokines with the concurrent or sequential administration of chemotherapeutic drugs.

In a prospective randomized trial published in 2005, the German Cooperative Renal Carcinoma Chemoimmunotherapy Group (DGCIN) investigated the combination of IL-2, IFN- $\alpha 2$ a and 5 -fluorouracil versus observation following radical tumor nephrectomy in 203 patients at high risk of relapse. At a median follow up of 4.3 years, OS was significantly lower in the treated group compared to the control group $(\mathrm{P}=0.028)$. Furthermore, the median survival without relapse was 2.75 years in the treated and 4.25 in the control group. Stage-adapted subanalyses revealed no survival advantages of treatment over observation. The results established that there was no RFS benefit; indeed, the adjuvant immunochemotherapy was detrimental to survival in the treatment arm. ${ }^{66}$

A successive phase III randomized trial was performed by the European Organization for Research and Treatment of Cancer (EORTC, protocol 30955), reconsidering adjuvant chemoimmunotherapy with a regimen based on IL-2, IFN $\alpha$ and 5-fluorouracil versus observation in 309 patients with high risk of relapse after surgical treatment for RCC. The study showed discontinuation of therapy in $35 \%$ due to toxicity, with a persistent deficit in fatigue and physical function. The 3 -year DFS was $50 \%$ in controls versus $61 \%$ in the treatment arm $(\mathrm{HR}=0.84$, 95\% CI 0.63-1.12); the 5-year OS was $63 \%$ among controls and $70 \%$ in treated patients ( $\mathrm{HR}=0.86,95 \% \mathrm{CI} 0.60-1.22)$. These final results, presented at the 2011 ASCO Annual Meeting, discourage the use of adjuvant chemoimmunotherapy for RCC because of significant toxicity without any statistically significant benefit for the adjuvant treament. ${ }^{67}$

\section{Other systemic adjuvant therapies}

The ability of medroxyprogesterone acetate (MPA) to block glucocorticoid receptors on some RCC cells, and to produce responses in some patients, provided the rationale for tests to be carried out on adjuvant hormonal therapy ${ }^{68}$ More than 20 years ago, the only multicenter Italian phase III trial studied adjuvant MPA three times a week for one

Table 3. Adjuvant chemotherapy and chemoimmunotherapy trials in renal cell cancer.

\begin{tabular}{|c|c|c|c|c|c|}
\hline Author & $\begin{array}{l}\text { No. } \\
\text { patients }\end{array}$ & Stage & Treatment & $\begin{array}{l}\text { Primary } \\
\text { end point }\end{array}$ & Results \\
\hline $\begin{array}{l}\text { Masuda } \\
\text { et al., } 1992^{65}\end{array}$ & 31 & $\begin{array}{l}\text { Stage I, II } \\
\text { or III }\end{array}$ & $\begin{array}{c}\text { VNBL+ } \\
\text { DOXO+UFT }\end{array}$ & OS & $\begin{array}{l}\text { Improvement } \\
\text { in the 5-year OS }\end{array}$ \\
\hline $\begin{array}{l}\text { Atzpodien } \\
\text { et al., } 200566\end{array}$ & 203 & $\begin{array}{l}\text { pT3b/c-T4, } \\
\text { N1-3, } \\
\text { resected M1 }\end{array}$ & $\begin{array}{c}\text { IL-2+IFN- } \alpha- \\
2 a+5-F U\end{array}$ & OS & Detrimental in OS \\
\hline $\begin{array}{l}\text { Aitchison } \\
\text { et al.,201167 }\end{array}$ & 309 & $\begin{array}{l}\text { High risk } \\
\text { patients a }\end{array}$ & $\begin{array}{l}\text { IL-2+IFN- } \alpha+ \\
\text { and 5-fluorouracil }\end{array}$ & DFS & $\begin{array}{l}\text { No difference in OS } \\
\text { No difference in DFS }\end{array}$ \\
\hline
\end{tabular}

IL-2, interleukin-2; IFN- $\alpha$, interpheron- $\alpha$; 5-FU, 5-fluorouracil; VNBL, vinblastine; DOXO, doxorubicin; UFT, tegafur-uracil; OS, overall survival; DFS, disease free survival. 
year, following radical nephrectomy for M0 renal cancer. ${ }^{69}$ The study, including patients with any T stage and also patients with lymph node involvement, randomized 136 patients to receive MPA $500 \mathrm{mg}$ orally three times per week versus observation. At a median follow up of three years, $26 \%$ of patients in the treatment arm had a recurrence, compared with $24 \%$ of patients in the control arm; recurrence was more frequent in tumors without estrogen receptors. Treatment was associated with significant systemic toxicity without any benefit; the hormonal strategy was, therefore, completely abandoned after this first approach.

More recently, thalidomide has also been evaluated in 46 patients in a randomized phase III trial conducted by the MD Anderson Cancer Center. After a median follow up of 43.9 months, patients on the thalidomide arm had inferior 2- and 3-year probabilities of RFS compared with controls ( $47.8 \%$ vs $69.3 \%$ and $28.7 \%$ vs $69.3 \%$, respectively; $\mathrm{P}=0.022$ ); the cancer-specific survival was similar for both groups. In conclusion, postoperative treatment with thalidomide for high-risk RCC is detrimental to RFS rates and did not improve cancer-specific death rates. ${ }^{70}$

\section{Ongoing trials into targeted therapy in an adjuvant setting}

The inhibition of angiogenesis using targeted therapies is a promising strategy in most solid tumors and appears to be particularly attractive in RCC. At present, three classes of drugs with antiangiogenic activity have been approved and extensively studied for this tumor: circulating VEGF inhibitors, such as bevacizumab; multi-targeted receptor tyrosine-kinase inhibitors (TKIs) of VEGFR, such as sunitinib, sorafenib, pazopanib and axitinib; inhibitors of mammalian target of rapamycin (mTOR) related to protein synthesis and to angiogenesis, such as temsirolimus and everolimus. ${ }^{14,71-76}$

The next logical step would be to test them in the adjuvant setting and several studies are currently ongoing to assess this possibility. On the other hand, a potential negative effect of anti-VEGF drugs when used for this purpose has been suggested since some studies proved an alteration in the host microenvironment that may facilitate the development of metastases.$^{77}$ Other pre-clinical evidence seems to indicate that while TKIs can reduce primary tumor growth, they can also promote tumor invasiveness and metastasis. ${ }^{78,79}$ For these reasons, which, however, have yet to be assessed, targeted agents in the adjuvant setting should only be administered in the context of a clinical trial.

No article concerning the new targeted drugs has been published so far, but several phase III adjuvant trials on RCC are currently underway with sorafenib, sunitinib, everolimus and pazopanib (Table 4)..$^{80-90}$ At present, the use of inhibitors of tyrosine kinase of VEGFR is being tested by different ongoing adjuvant trials. One of these is represented by a randomized double-blind trial comparing one year versus three years of sorafenib versus three years of placebo in 1656 patients at high or intermediate risk (the SORCE trial, estimated completion date in 2012). ${ }^{81}$ A second trial is ongoing with sunitinib for one year versus placebo for patients at high risk of recurrent RCC after complete resection (S-TRAC, estimated completion date in 2015) ${ }^{82}$ In the long term, the purpose of the ASSURE trial was to test sunitinib compared to sorafenib or placebo in more than 1900 completely resected RCC patients. The primary objective of this trial is DFS; the estimated completion date is April 2016. ${ }^{80}$

Another ongoing randomized phase III clinical trial with targeted drugs is the EVEREST study. This is being conducted by the Southwest Oncology Group (SWOG-S0931) comparing 1-year everolimus versus placebo in high and very high-risk RCC groups. Primary end point is RFS, OS and translational studies are secondary end points, and the estimated completion date is in 2016. ${ }^{87,88}$ Another notable ongoing study is the PROTECT trial. This is a randomized, double blind, phase III study evaluating pazopanib versus placebo in the prevention or delay of postoperative recurrence of RCC in patients with moderately high or high risk. Primary end point is DFS, the secondary outcome measurements are OS, DFS rates at yearly time points, safety and health; the estimated completion date is in $2017.89,90$

Finally, in 2004, an international randomized phase III trial, ARISER (adjuvant rencarex immunotherapy trial to study efficacy in nonmetastatic RCC), began accrual to evaluate cG250 (WX-G250, Rencarex $^{\circledR}$, Wilex Pharmaceuticals, Munich, Germany) versus placebo after nephrectomy in patients with high-risk non-metastatic clear cell RCC. G250 is a monoclonal antibody against G250, a transmembrane protein associated with RCC, which is identical to CAIX; the monoclonal immunoglobulin G1 cG250 is an intravenously administered antibody that binds to CAIX on clear cell RCC and may recruit effector cells or activate complement to result in cell death. The study, not yet published, reached a total of 864 patients..$^{83-86}$

\section{Conclusions}

The recent innovations in the treatment of metastatic RCC, with the setting of new standards and the improvement in OS to over 17 months, ${ }^{91}$ has suggested the usefulness of investigating these same strategies in the adjuvant setting in the hope that the progress seen in metastatic disease trials will also be made in this context.

Up to now, only an autologous vaccine has shown some benefit among all the systemic therapies tested so far in the adjuvant setting. ${ }^{56,60}$ and some subgroups of patients at low risk could benefit from low doses of IL- 2 and IFN- $\alpha .{ }^{48}$ These few data, although significant, require further validation and have yet to change the standard after radical nephrectomy, since the actual standard of care after radical

Table 4. Phase III ongoing trials in adjuvant renal cell cancer.

\begin{tabular}{|c|c|c|c|}
\hline Study name & Histology & Risk/stage & Trial design \\
\hline ASSURE $^{80}$ & All & pT1b G3-4, pT2-4, N+ & Sorafenib vs sunitinib vs placebo \\
\hline SORCE $^{81}$ & All & High and intermediate risk & 1-year sorafenib vs 3 -year sorafenib vs placebo \\
\hline S-TRAC ${ }^{82}$ & Predominant clear cell & High risk (UISS criteria) & Sunitinib vs placebo \\
\hline ARISER ${ }^{83-86}$ & Clear cell & $\begin{array}{l}\text { Tlb or T2, N0/NX, M0, each with } \mathrm{G} \geq 3 \text {, } \\
\text { or T3a/b/c, or T4 N0/NX, M0, or any T stage and N+M0 }\end{array}$ & Monoclonal chimeric antibody cG250 vs placebo \\
\hline EVEREST 87,88 & All & Intermediate high risk or very high risk & Everolimus vs placebo \\
\hline PROTECT ${ }^{89,90}$ & $\begin{array}{l}\text { Clear-cell or predominant } \\
\text { clear-cell }\end{array}$ & $\begin{array}{l}\text { pT2, G3 or G4, N0; or pT3, G any, N0; or pT4, G any, } \\
\text { N0; or pT any, G any, N1 }\end{array}$ & Pazopanib us placebo \\
\hline
\end{tabular}

UISS, University of California Los Angeles Integrated Staging System. 
nephrectomy is still only observation.

Enrollment in randomized clinical trials after radical resection of RCC should be encouraged and offered to all patients eligible; an appropriate selection of patients who would benefit from adjuvant therapies remains a crucial dilemma, in particular identifying prognostic factors which might better predict the risk of relapse.

The hope of improving survival after nephrectomy has been renewed with the emerging role of targeted therapies which are currently at the forefront of new studies in an adjuvant setting for RCC. Although the international guidelines do not actually recommend any adjuvant treatment after radical RCC surgery, there is still no last word on this, pending the results of the promising ongoing clinical trials with the angiogenesis and mTOR inhibitors. The significant changes that these new drugs have made on advanced disease outcome could represent the key to innovation in terms of preventing recurrence, delaying relapse and prolonging survival after radical surgery for RCC.

\section{References}

1. Gupta K, Miller JD, Li JZ, et al. Epidemiologic and socioeconomic burden of metastatic renal cell carcinoma (mRCC): a literature review. Cancer Treat Rev 2008;34:193-205.

2. Jemal A, Siegel R, Ward E. Cancer statistics, 2008. CA Cancer J Clin 2008;58:71-96.

3. Seer.cancer.gov [Internet]. SEER Stat Fact Sheets: kidney and renal pelvis [updated 2002 November 10]. http://seer.cancer.gov/statfacts/html/kidrp.html Accessed: March 20, 2012.

4. Brennan P, van der Hel 0, Moore LE. Tobacco smoking, body mass index, hypertension, and kidney cancer risk in central and eastern Europe. Br J Cancer 2008;99:1912-5.

5. Chow WH, Gridley G, Fraumeni IF, Järvholm B. Obesity, hypertension, and the risk of kidney cancer in men. $\mathrm{N}$ Engl $\mathrm{J}$ Med 2000;343:1305-11.

6. Benichou J, Chow WH, McLaughlin JK, et al. Population attributable risk of renal cell cancer in Minnesota. Am $\mathrm{J}$ Epidemiol 1998;148:424-30.

7. Gettman MT, Blute ML, Spotts B, et al. Pathologic staging of renal cell carcinoma: Significance of tumor classification with the 1997 TNM staging system. Cancer 2001;91:354-61.

8. Marszalek M, Meixl H, Polajnar M, et al. Laparoscopic and open partial nephrectomy: a matched-pair comparison of 200 patients. Eur Urol 2009;181:170-6.

9. Breda A, Finelli A, Janetschek G, et al. Complications of laparoscopic surgery for renal masses: prevention, management, and comparison with the open experience. Eur Urol 2009;55:836-50.

10. Garg S, Batura D, Biyani CS, Gill I. Laparoscopic surgery for cancers of the kidney: Long-term oncological efficacy. BJU Int 2008; 102:1498-501.

11. Butler BP, Novick AC, Miller DP, et al. Management of small unilateral renal cell carcinomas: radical versus nephron-sparing surgery. Urology 1995;45:34-40.

12. Lerner SE, Hawkins CA, Blute ML, et al. Disease outcome in patients with low stage renal cell carcinoma treated with nephron sparing or radical surgery. J Urol 1996;155:1868-73.

13. Edge SB, Byrd DR, Compton CC, Fritz AG, Greene FL, Trotti A, (eds). AJCC Cancer Staging Manual. 6th Printing. Berlin: Springer Verlag; 2010.

14. Motzer RJ, Hutson TE, Tomczak P, et al. Sunitinib versus interferon alfa in metastatic renal-cell carcinoma. $\mathrm{N}$ Engl $\mathrm{J}$ Med 2007;356:115-24.

15. Motzer RJ, Bander NH, Nanus DM. Renal-cell carcinoma. N Engl J
Med 1996;335:865-75.

16. Lam JS, Shvarts 0, Leppert JT, et al. Renal cell carcinoma 2005: new frontiers in staging, prognostication and targeted molecular therapy. J Urol 2005;173:1853-62.

17. Fuhrman SA, Lasky LC, Limas C. Prognostic significance of morphologic parameters in renal cell carcinoma. Am J Surg Path 1982;6:655-63.

18. Kontak JA, Campbell SC. Prognostic factors in renal cell carcinoma. Urol Clin North Am 2003;30:467-80.

19. Patard JJ, Leray E, Rioux-Leclercq N, et al. Prognostic value of histologic subtypes in renal cell carcinoma: a multicenter experience. J Clin Oncol 2005;23:2763-71.

20. Dall'Oglio MF, Antunes AA, Sarkis AS, et al. Microvascular tumour invasion in renal cell carcinoma: the most important prognostic factor. BJU Int 2007;100:552-5.

21. Cheville JC, Lohse CM, Zincke H, et al. Comparisons of outcome and prognostic features among histologic subtypes of renal cell carcinoma. Am J Surg Pathol 2003;27:612-24.

22. Frank I, Blute ML, Cheville JC, et al. A multifactorial postoperative surveillance model for patients with surgically treated clear cell renal cell carcinoma. J Urol 2003;170:2225-32.

23. Chowdhury S, Larkin JM, Gore ME. Recent advances in the treatment of renal cell carcinoma and the role of targeted therapies. Eur J Cancer 2008;44:2152-61.

24. Kim SP, Weight CJ, Leibovich BC, et al. Outcomes and clinicopathologic variables associated with late recurrence after nephrectomy for localized renal cell carcinoma. Urology 2011;78:1101-6.

25. Pantuck AJ, Zeng G, Belldegrun AS, Figlin RA. Pathobiology, prognosis, and targeted therapy for renal cell carcinoma: exploiting the hypoxia-induced pathway. Clin Cancer Res 2003;9:4641-52.

26. Leppert JT, Lam JS, Pantuck AJ, et al. Carbonic anhydrase IX and the future of molecular markers in renal cell carcinoma. BJU Int 2005;96:281-5.

27. Bui MH, Seligson D, Han KR, et al. Carbonic anhydrase IX is an independent predictor of survival in advanced renal clear cell carcinoma: implications for prognosis and therapy. Clin Cancer Res 2003;9:802-11.

28. Soyupak B, Erdogan S, inventors. MN/CA IX/CA9 and renal cancer prognosis. United States Patent: US 20090191557; 2009.

29. Patard J, Fergelot P, Karakiewicz PI, et al. Low CAIX expression and absence of VHL gene mutation are associated with tumour aggressiveness and poor survival. Int J Cancer 2008;123:395-400.

30. Finley DS, Pantuck AJ, Belldegrun AS. Tumor biology and prognostic factors in renal cell carcinoma. Oncologist 2011;16 Suppl 2:4-13.

31. Takahashi M, Rhodes DR, Furge KA, et al. Gene expression profiling of clear cell renal cell carcinoma: gene identification and prognostic classification. Proc Natl Acad Sci U S A 2001;98:9754-9.

32. Sorbellini M, Kattan MW, Snyder ME, et al. A postoperative prognostic nomogram predicting recurrence for patients with conventional clear cell renal cell carcinoma. J Urol 2005;173:48-51.

33. Zisman A, Pantuck AJ, Dorey F, et al. Mathematical model to predict individual survival for patients with renal cell carcinoma. J Clin Oncol 2002;20:1368-74.

34. Frank I, Blute ML, Cheville JC. An outcome prediction model for patients with clear cell renal cell carcinoma treated with radical nephrectomy based on tumor stage, size, grade and necrosis: the SSIGN score. J Urol 2002;168:2395-400.

35. Karakiewicz PI, Briganti A, Chu FK, et al. Multi-institutional validation of a new renal cancer-specific survival nomogram. J Clin Oncol. 2007;25(11):1316-22.

36. Leibovich BC, Blute ML, Cheville JC, et al. Prediction of progression after radical nephrectomy for patients with clear cell renal cell carcinoma: a stratification tool for prospective clinical trials. Cancer 2003;97:1663-71. 
37. Pichler M, Hutterer GC, Chromecki TF, et al. External validation of the Leibovich prognosis score for nonmetastatic clear cell renal cell carcinoma at a single European center applying routine pathology. J Urol 2011;186:1773-7.

38. Pichler M, Hutterer GC, Chromecki TF, et al. Prognostic value of the Leibovich prognosis score supplemented by vascular invasion for clear cell renal cell carcinoma. J Urol 2012;187:834-9.

39. Ficarra V, Novara G, Galfano A, et al. The 'Stage, Size, Grade and Necrosis' score is more accurate than the University of California Los Angeles Integrated Staging System for predicting cancer-specific survival in patients with clear cell renal cell carcinoma. BJU Int 2009;103:165-70.

40. Tan MH, Kanesvaran R, Li H, et al. Comparison of the UCLA Integrated Staging System and the Leibovich score in survival prediction for patients with nonmetastatic clear cell renal cell carcinoma. Urology 2010;75:1365-70.

41. Tan MH, Li H, Choong CV, et al. The Karakiewicz nomogram is the most useful clinical predictor for survival outcomes in patients with localized renal cell carcinoma. Cancer 2011;117:5314-24.

42. NCCN.org [Internet]. Clinical Practice Guidelines in Oncology (NCCN Guidelines). Version 1.2012. http:/www.nccn.org/professionals/physician_gls/f_guidelines.asp\#kidney Accessed: March 20, 2012.

43. Scherr AJ, Lima JP, Sasse EC, et al. Adjuvant therapy for locally advanced renal cell cancer: a systematic review with meta-analysis. BMC Cancer 2011;11:115.

44. Bleumer I, Oosterwijk E, De Mulder P, Mulders PF. Immunotherapy for renal cell carcinoma. Eur Urol 2003;44:65-75.

45. Pizzocaro G, Piva L, Colavita M, et al. Interferon adjuvant to radical nephrectomy in Robson stages II and III renal cell carcinoma: a multicentric randomized study. J Clin Oncol 2001;19:425-31.

46. Clark JI, Atkins MB, Urba WJ, et al. Adjuvant high-dose bolus interleukin-2 for patients with high-risk renal cell carcinoma: a cytokine working group randomized trial. J Clin Oncol 2003;21:3133-40.

47. Messing EM, Manola J, Wilding G, et al. Phase III study of interferon alfa-NL as adjuvant treatment for resectable renal cell carcinoma: an Eastern Cooperative Oncology Group/Intergroup trial. J Clin Oncol 2003;21:1214-22.

48. Passalacqua R, Buzio C, Buti S, et al. Adjuvant low-dose interleukin-2 (IL2) plus interferone-alpha (IFN) in operable renal cell cancer (RCC). A phase III, randomized, multicenter, independent trial of the Italian Oncology Group for Clinical Research (GOIRC). J Clin Oncol 2007;25:965s, Abstract LBA5028.

49. Hinotsu S, Kawai K, Ozono S, et al. Randomized controlled study of natural interferon $\alpha$ as adjuvant treatment for stage II or III renal cell carcinoma. Int J Clin Oncol 2011. [Epub ahead of print].

50. McDermott DF. Immunotherapy of metastatic renal cell carcinoma. Cancer 2009;15: 115 Suppl 10:2298-305.

51. Pyrhonen S, Salminen E, Ruutu M, et al. Prospective randomized trial of interferon alfa-2a plus vinblastine versus vinblastine alone in patients with advanced renal cell cancer. J Clin Oncol 1999;17:2859-67.

52. Medical Research Council Renal Cancer Collaborators. Interferonalpha and survival in metastatic renal carcinoma: early results of a randomised controlled trial. Lancet 1999;353:14-7.

53. Amato R. Modest effect of interferon alfa on metastatic renal-cell carcinoma. Lancet 1999;353:6-7.

54. Fisher RI, Rosenberg SA, Sznol M, et al. High-dose aldesleukin in renal cell carcinoma: Long-term survival update. Cancer J Sci Am 1997;3:S70-2.

55. Galligioni E, Quaia M, Merlo A, et al. Adjuvant immunotherapy treatment of renal carcinoma patients with autologous tumor cells and bacillus Calmette-Guerin: five-year results of a prospective randomized study. Cancer 1996;77:2560-6.
56. Jocham D, Richter A, Hoffmann L, et al. Adjuvant autologous renal tumour cell vaccine and risk of tumour progression in patients with renal-cell carcinoma after radical nephrectomy: Phase III, randomised controlled trial. Lancet 2004;363:594-9.

57. Wood C, Srivastava P, Bukowski R, et al. An adjuvant autologous therapeutic vaccine (HSPPC-96; vitespen) versus observation alone for patients at high risk of recurrence after nephrectomy for renal cell carcinoma: a multicentre, open-label, randomised phase III trial. Lancet 2008;372:145-54.

58. Passalacqua R, Buti S, Tomasello G, et al. Immunotherapy options in metastatic renal cell cancer: where we are and where we are going. Exp Rev Anticancer Ther 2006;6:1459-72.

59. Wood CG. Multimodal approaches in the management of locally advanced and metastatic renal cell carcinoma: combining surgery and systemic therapies to improve patient outcome. Clin Cancer Res 2007;13:697-702.

60. Doehn C, Richter A, Theodor RA, et al. An adjuvant vaccination with Reniale ${ }^{\circledR}$ prolongs survival in patients with renal cell carcinoma following radical nephrectomy: secondary analysis of a multicenter phase-III trial. J Urol 2007;177:167S, Abstract 500.

61. Asakura T, Imai A, Ohkubo-Uraoka N, et al. Relationship between expression of drug-resistance factors and drug sensitivity in normal human renal proximal tubular epithelial cells in comparison with renal cell carcinoma. Oncol Rep 2005;14:601-7.

62. Waters JS, Moss C, Pyle L, et al. Phase II clinical trial of capecitabine and gemcitabine chemotherapy in patients with metastatic renal carcinoma. Br J Cancer 2004;91:1763-8.

63. Stadler WM, Halabi S, Rini BI, et al. A phase II study of gemcitabine and capecitabine in metastatic renal cancer: a report of Cancer and Leukemia Group B protocol 90008. Cancer 2006;107:1273-9.

64. Lilleby $W$ and Fossa SD. Chemotherapy in metastatic renal cell cancer. World J Urol 2005;23:175-9.

65. Masuda F, Nakada J, Kondo I, Furuta N. Adjuvant chemotherapy with vinblastine, adriamycin, and UFT for renal-cell carcinoma. Cancer Chemother Pharmacol. 1992;30: 477-9.

66. Atzpodien J, Schmitt E, Gertenbach U, et al. Adjuvant treatment with interleukin-2- and interferon-alpha2a-based chemoimmunotherapy in renal cell carcinoma post tumour nephrectomy: results of a prospectively randomised trial of the German Cooperative Renal Carcinoma Chemoimmunotherapy Group (DGCIN). Br J Cancer 2005;92:843-6.

67. Aitchison M, Bray CA, Van Poppel H, et al. Final results from an EORTC (GU Group)/NCRI randomized phase III trial of adjuvant interleukin-2, interferon alpha, and 5-fluorouracil in patients with a high risk of relapse after nephrectomy for renal cell carcinoma (RCC). Proc ASCO 2011 Annual Meeting, USA. J Clin Oncol 2011;29 Suppl 15:4505. [Abstract].

68. Pizzocaro G, Piva L, Salvioni R, et al. Adjuvant medroxyprogesterone acetate and steroid hormone receptors in category M0 renal cell carcinoma. An interim report of a prospective randomized study. J Urol 1986;135:18-21.

69. Pizzocaro G, Piva L, Di Fronzo G, et al. Adjuvant medroxyprogesterone acetate to radical nephrectomy in renal cancer: 5-Year results of a prospective randomized study. J Urol 1987;138:1379-81.

70. Margulis V, Matin SF, Tannir N, et al. Randomized trial of adjuvant thalidomide versus observation in patients with completely resected high-risk renal cell carcinoma. Urology 2009;73:337-41.

71. Escudier B, Eisen T, Stadler WM, et al. Sorafenib in advanced clearcell renal-cell carcinoma. N Engl J Med 2007;356:125-34.

72. Escudier B, Pluzanska A, Koralewski P, et al. Bevacizumab plus interferon alfa-2a for treatment of metastatic renal cell carcinoma: a randomised, double-blind phase III trial. Lancet 2007;370:210311.

73. Hudes G, Carducci M, Tomczak P, et al. Temsirolimus, interferon 
alfa, or both for advanced renal-cell carcinoma. N Engl J Med 2007;356:2271-81.

74. Motzer RJ, Hutson TE, Tomczak P, et al. Efficacy of everolimus in advanced renal cell carcinoma: A double-blind, randomised, placebo-controlled phase III trial. Lancet 2008;372:449-56.

75. Sternberg CN, Davis ID, Mardiak J, et al. Pazopanib in locally advanced or metastatic renal cell carcinoma: results of a randomized phase III trial. J Clin Oncol 2010;28:1061-8.

76. Rini BI, Escudier B, Tomczak P, et al. Comparative effectiveness of axitinib versus sorafenib in advanced renal cell carcinoma (AXIS): a randomised phase 3 trial. Lancet 2011;378:1931-9.

77. Plimack ER, Tannir N, Lin E, et al. Patterns of disease progression in metastatic renal cell carcinoma patients treated with antivascular agents and interferon: impact of therapy on recurrence patterns and outcome measures. Cancer 2009;115:1859-66.

78. Ebos JM, Lee CR, Cruz-Munoz W, et al. Accelerated metastasis after short-term treatment with a potent inhibitor of tumorangiogenesis. Cancer Cell 2009;15:232-9.

79. Paez-Ribes M, Allen E, Hudock J, et al. Antiangiogenic therapy elicits malignant progression of tumors to increased local invasion and distant metastasis. Cancer Cell 2009;15:220-31.

80. ClinicalTrials.gov [Internet]. Sunitinib or sorafenib in treating patients with kidney cancer that was removed by surgery. ClinicalTrials.gov registration number: NCT00326898. http://www.clinicaltrials.gov Accessed: March 20, 2012.

81. ClinicalTrials.gov [Internet]. Sorafenib in treating patients at risk of relapse after undergoing surgery to remove kidney cancer. ClinicalTrials.gov registration number: NCT00492258. http://www.clinicaltrials.gov Accessed: March 20, 2012.

82. ClinicalTrials.gov [Internet]. A clinical trial comparing efficacy and safety of sunitinib versus placebo for thetreatment of patients at high risk of recurrent renal cell cancer (S-TRAC). ClinicalTrials.gov registration number: NCT00375674. http://www.clinicaltrials.gov Accessed: March 20, 2012.
83. Liao SY, Aurelio ON, Jan K, et al. Identification of the MN/CA9 protein as a reliable diagnostic biomarker of clear cell carcinoma of the kidney. Cancer Res 1997;57:2827-31.

84. Lam JS, Leppert JT, Belldegrun AS, Figlin RA. Adjuvant therapy of renal cell carcinoma: patient selection and therapeutic options. BJU Int 2005;96:483-8.

85. Sokoloff MH, Daneshmand S, Ryan CW. Current clinical trials in renal cell carcinoma. Urol Oncol 2005;23:289-92.

86. ClinicalTrials.gov [Internet]. Monoclonal antibody therapy (Rencarex®) in treating patients who have undergone surgery for non-metastatic kidney cancer. ClinicalTrials.gov registration number: NCT00087022. http://www.clinicaltrials.gov Accessed: March 20, 2012.

87. ClinicalTrials.gov [Internet]. Everolimus in treating patients with kidney cancer who have undergone surgery. ClinicalTrials.gov registration number: NCT01120249. http://www.clinicaltrials.gov Accessed: March 20, 2012.

88. Homicsko K, Berthold DR. Neoadjuvant and adjuvant strategies in renal cell carcinoma: more questions than answers. Anticancer Drugs 2011;22 Suppl 1:S4-8.

89. ClinicalTrials.gov [Internet]. A Study to evaluate pazopanib as an adjuvant treatment for localized renal cell carcinoma (RCC) (PROTECT). ClinicalTrials.gov registration number: NCT01235962. http://www.clinicaltrials.gov Accessed: March 20, 2012.

90. Rexer H. Adjuvante AUO-Studie beim Nierenzellkarzinom nach (Teil) Nephrektomie. Randomisierte, doppelblinde, placebokontrollierte Phase-III-Studie (PROTECT - AN 30/10) zur Untersuchung der Wirksamkeit und Sicherheit von Pazopanib als adjuvante Therapie bei Patienten mit lokalisiertem oder lokal fortgeschrittenem Nierenzellkarzinom nach Nephrektomie. Urologe 2011;50:489-91.

91. Reeves DJ, Liu CY. Treatment of metastatic renal cell carcinoma. Cancer Chemother Pharmacol 2009;64:11-25. 